\title{
ORIGEM E CONFORMAÇÃO DO CAMPO DA NUTRIÇÃO EM SAÚDE PÚBLICA EM PERNAMBUCO: UMA ANÁLISE HISTÓRICO-ESTRUTURAL'
}

\section{THE ORIGIN AND CONFIGURATION OF THE FIELD OF NUTRITION IN PUBLIC HEALTH IN PERNAMBUCO: A HISTORIC-STRUCTURAL ANALYSIS}

Francisco de Assis Guedes de VASCONCELOS 2

RESUMO

O objetivo deste trabalho foi investigar o processo de constituição do campo da Nutrição em Saúde Pública em Pernambuco, no período 1930-1982, correspondente à trajetória acadêmica de Nelson Chaves, fundador do Curso de Nutricionistas e do Instituto de Nutrição da Universidade Federal de Pernambuco. A metodologia consistiu na análise das fontes escritas existentes, representadas pelas publicações dos cientistas envolvidos. A análise destas fontes sugere que a conformação deste campo científico constituiu um processo complexo, definido sob a influência de diferentes interesses, produzidos interna e externamente pela comunidade científica investigada. Por fim, procuramos demonstrar como um grupo de cientistas, a partir das suas preocupações em buscar soluções para a problemática da desnutrição infantil em Pernambuco, construiu o que chamamos de paradigma ecológico-humanista nutricional, contribuindo para a institucionalização do campo da Nutrição em Saúde Pública no Brasil.

Termos de indexação: nutrição, saúde pública, história da nutrição, produção científica.

\begin{abstract}
The objective of this study was to investigate the process that established the field of Nutrition in Public Health in the state of Pernambuco (Brazil), from 1930 to 1982. This period corresponds to the academic path of Nelson Chaves, founder of the Nutritionists School and of the Institute of Nutrition of the Federal University of Pernambuco. The methodology was based on the analysis of existing written sources, represented by the publications of the scientists involved. The analysis of the sources suggests that the configuration of this scientific field constituted a complex process, defined by the influence of distinct interests, produced both internally and externally by the scientific
\end{abstract}

(1) Versão simplificada de tese de doutorado em Saúde Pública, intitulada "Como Nasceram os Meus Anjos Brancos: A Constituição do Campo da Nutrição em Saúde Pública em Pernambuco", Escola Nacional de Saúde Pública, Fundação Oswaldo Cruz, 1999.

(2) Departamento de Nutrição, Centro de Ciências da Saúde, Universidade Federal de Santa Catarina. Campus Universitário, Trindade, 88040 -970, Florianópolis, SC, Brasil.E-mail:fguedes@floripa.com.br 
community investigated. Finally, this work tries to show how a specific group of scientists, starting from their own concerns to seek solutions to children's malnutrition in the state of Pernambuco, created what is commonly called the nutritional humanistecological paradigm, thus contributing to the institutionalization of the field of Nutrition in Public Health in Brazil.

Index terms: nutrition, public health, history of nutrition, scientific production.

\section{INTRODUÇÃO}

No Brasil, a emergência do campo da Nutrição seja como disciplina, política social e/ou profissão, tem sido contextualizada no bojo das transformações econômico-político-sociais e culturais que o país vivenciou nos anos 1930-1940. Entretanto, é preciso registrar que, como desdobramento da chamada Higiene Alimentar, uma área de estudo surgida no interior das Faculdades de Medicina da Bahia e do Rio de Janeiro, por volta da segunda metade do século XIX, a institucionalização acadêmica deste campo levou quase cem anos para ocorrer. Ao longo deste processo, dentro do conjunto de atores envolvidos com a sua constituição, particularmente entre os chamados médicos nutrólogos, encontramse aqueles que integraram-se ao chamado movimento sanitarista da Primeira República ou que sofreram as suas influências. Assim, neste seu nascedouro, tanto no Rio de Janeiro como em São Paulo, pelo menos duas correntes bem definidas e distintas do saber médico confluíram-se para a conformação e simultaneamente para o estabelecimento dos pontos de tensão deste campo. Por um lado, a chamada vertente biológica, com orientação para estudos clínicoexperimentais e laboratoriais. Esta vertente, a partir de 1940, deu origem à Nutrição Clínica (Dietoterapia), considerada a especialização-matriz do campo da Nutrição dentro do contexto mundial, voltada ao desenvolvimento de ações, de caráter individual, centradas no alimento como agente de tratamento, bem como à Nutrição Básica e Experimental, uma outra especialização, voltada ao desenvolvimento de pesquisas básicas de caráter experimental e laboratorial. De outro lado, a chamada vertente social, com orientação para estudos dietético-nutricionais de populações. Esta vertente, a partir dos anos 40s, deu origem à Alimentação Institucional (Alimentação Coletiva), também considerada como uma especialização-matriz do campo da Nutrição, voltada à administração, no sentido de racionalização, da alimentação de coletividades sadias e enfermas, bem como à Nutrição em Saúde Pública, uma outra especialização, voltada ao desenvolvimento de ações de caráter coletivo, no sentido de contribuir para garantir que a produção e distribuição de alimentos seja adequada e acessível a todos os indivíduos da sociedade (Coimbra et al., 1982; L'Abbate, 1982; Ypiranga \& Gil, 1989; Vasconcelos, 1999a).
Em relação ao processo de formação do nutricionista brasileiro, observamos que o mesmo teve seu início na década de 1940, quando foram criados os quatro primeiros cursos do País. Em 1939, por iniciativa do médico Geraldo Horácio de Paula Souza, foi criado o primeiro curso no Instituto de Higiene de São Paulo (atual Curso de Graduação em Nutrição do Departamento de Nutrição da Faculdade de Saúde Pública da Universidade de São Paulo - USP). Em 1940, tiveram início os cursos técnicos do Serviço Central de Alimentação do Instituto de Aposentadorias e Pensões dos Industriários (IAPI), que deram origem, em 1943, sob a direção do médico Dante Nascimento Costa, ao Curso de Nutricionistas do Serviço de Alimentação da Previdência Social (SAPS) (atual Curso de Graduação em Nutrição da Universidade do Rio de Janeiro - UNI-RIO). Em 1944, foi criado o Curso de Nutricionistas da Escola Técnica de Assistência Social Cecy Dodsworth (atual Curso de Graduação em Nutrição da Universidade Estadual do Rio de Janeiro - UERJ). Em 1946, por iniciativa de Josué de Castro foi criado o Instituto de Nutrição da Universidade do Brasil, onde, a partir de 1948, teve início o Curso de Dietistas (atual Curso de Graduação em Nutrição do Instituto de Nutrição da Universidade Federal do Rio de Janeiro - UFRJ).

Na década de 1950, mais dois cursos foram criados. Em 1956, por iniciativa do médico Adriano de Azevedo Pondé, foi criado o Curso de Nutricionistas da Universidade da Bahia (atual Curso de Graduação em Nutrição da Escola de Nutrição da Universidade Federal da Bahia - UFBA). E em 1957, por iniciativa do médico Nelson Ferreira de Castro Chaves, foi fundado o Curso de Nutricionistas do Instituto de Fisiologia e Nutrição da Faculdade de Medicina de Recife (atual Curso de Graduação em Nutrição do Departamento de Nutrição da Universidade Federal de Pernambuco - UFPE), apontado por alguns estudos como o primeiro curso brasileiro a formar profissionais voltados para atuação em Saúde Pública (Coêlho, 1983; Bosi, 1988).

No presente trabalho, partindo de uma determinada concepção teórica que concebe campo científico como um espaço de luta pelo monopólio da competência científica que é socialmente reconhecida a um agente determinado, ou seja, a capacidade técnica e o poder social de falar e intervir legitimamente em matéria de ciência (Bourdieu, 1994), apresentamos uma síntese dos 
resultados de uma investigação cujo objetivo foi analisar, de forma histórico-estrutural, como ocorreu em Pernambuco, nos anos 1950-1960, o processo de produção do corpo de conhecimentos científicos que garantiu especificidade ao campo da Nutrição em Saúde Pública; quem foram os agentes sociais construtores/ detentores destes conhecimentos; como ocorreu a aplicação prática que garantiu a legitimidade ou reconhecimento social deste campo; qual a interligação deste processo com antecedentes históricos verificados nos anos 1930-1940 e, finalmente, qual a sua influência sobre determinados acontecimentos ocorridos nas décadas seguintes. Tal investigação teve como eixo longitudinal de análise o período 1930-1982, correspondente à trajetória acadêmica de um dos seus protagonistas, o cientista Nelson Chaves. Ao eixo longitudinal investigado, sobrepõem-se quatro cortes transversais (os anos 1930-1949, 1950-1963, 1964-1972 e 1973-1982), correspondentes a contextos específicos, estabelecidos como critérios metodológicos de análise (Vasconcelos, 1999b).

\section{MATERIAL E MÉTODOS}

A metodologia utilizada para apreensão do objeto de estudo consistiu na análise de fontes orais, construídas com base na metodologia da história oral temática, e no estudo das fontes escritas existentes, representadas pelas publicações científicas dos sujeitos envolvidos. No presente artigo, nos reportamos apenas ao estudo de tais fontes escritas.

Tomamos como objeto central de análise a publicação Memória Científica do Departamento de Nutrição e das Instituições Predecessoras (1950-1995) (Costa, 1995b), um precioso registro histórico sistemático da produção científica dos docentes vinculados ao atual Departamento de Nutrição da UFPE, apresentando as listas anuais de títulos publicados, dentro de um eixo longitudinal que se inicia em 1932, ano da primeira publicação científica de Chaves, e que avança até outubro de 1995, ano da comemoração dos quarenta anos de fundação da referida instituição. Portanto, esta publicação constituiu a principal fonte escrita utilizada para analisar a trajetória da produção científica de Nelson Chaves e do grupo de cientistas que investigamos, vinculados ao campo da Nutrição em Saúde Pública, composto por Bertoldo Kruse Grande de Arruda, Emília Aureliano de Alencar Monteiro, Heloísa de Andrade Lima Coêlho, Malaquias Batista Filho, Maria Anunciada Ferraz de Lucena e Marly Cordeiro Baez.

\section{A Gestação (1930-1949)}

No Estado de Pernambuco, nos anos 1930-1949, observamos a existência de um considerável conjunto de pesquisas sobre as condições nutricionais da população, desenvolvido por importantes intelectuais envolvidos na história de constituição do campo da Nutrição no país, entre os quais destacamos: Gilberto Freyre, Jamesson Ferreira Lima, Josué de Castro, Nelson Chaves, Orlando Parahym e Ruy Coutinho.

O rastreamento das trajetórias acadêmicas de Freyre, Castro e Chaves, no decorrer destes anos, sinaliza a existência de elementos que contribuíram simultaneamente para identificação e diferenciação de suas obras. O primeiro elemento que apontamos diz respeito à questão das origens de classe social destes cientistas. Freyre e Chaves vinculavam-se à aristocracia agrária, mantida econômica e politicamente pela monocultura da cana-de-açúcar na Zona da Mata pernambucana. Castro, por sua vez, descendia de família de agricultor sertanejo que, em função das secas periódicas, migrou para a cidade do Recife, identificando-se com a classe média urbano-industrial emergente. Estes três autores tiveram seus processos de formação profissional fora do território pernambucano e ao longo da década de 1920. Freyre, entre 1917 a 1922, obteve sua graduação e pós-graduação no campo das Ciências Políticas e Sociais nos Estados Unidos da América, sendo particularmente influenciado pelo antropólogo Franz Boas. Castro, em 1929, concluiu o curso médico da Faculdade de Medicina da então Universidade do Brasil, no Rio de Janeiro, sendo particularmente influenciado pela Nutrologia do argentino Pedro Escudero e pela chamada Nova Geografia de Vidal de La Blache. Enquanto Chaves, formado médico, em 1930, pela Faculdade de Medicina do Rio de Janeiro, teve em seu processo de formação as influências da Fisiologia/Endocrinologia de Álvaro Ozório de Almeida, do espanhol Gregório Marañon e do argentino Bernardo Houssay. O segundo elemento que apontamos diz respeito ao contexto onde ocorreu o início do processo de atuação e produção acadêmico- profissional destes três cientistas - o Estado de Pernambuco, particularmente, a cidade do Recife, nos primeiros anos da década de 1930 (Castro, 1980; L'Abbate, 1982; Coêlho, 1983; Costa, 1995a; Magalhães, 1997; Freyre, 1998).

Em relação às divergências observadas entre Freyre e Castro, nos parece mais sensato afirmar, concordando com estudos anteriores (L'Abbate, 1982; Lima, 1997; Magalhães, 1997), que coube a Castro a introdução da discussão em torno do aprimoramento eugênico do povo brasileiro através de uma alimentação racional. Entretanto, com a publicação 
de Casa-Grande \& Senzala, em 1933, Freyre (1998) realizava o primeiro e então mais completo ensaio sociológico sobre o padrão e os hábitos alimentares da sociedade brasileira. Com sua abordagem sócio-cultural sobre o processo de miscigenação, enfatizando distinções entre influências genéticas (biológicas) e sociais, mais especificamente entre raça e cultura, Freyre (1998), introduziu conceitos inéditos na discussão sobre a inferioridade racial do mestiço brasileiro, apontando para a concepção da construção de uma identidade nacional brasileira, a partir da valorização da miscigenação das três raças - o branco, o negro e o índio.

Por sua vez, a análise das publicações de Chaves nos possibilitou a identificação de uma fase inicial, situada no período de 1932 a 1944, voltada exclusivamente à perspectiva biológica da Nutrição, particularmente ao estudo de aspectos fisiológicos e endocrinológicos de indivíduos. A emergência da abordagem social nos estudos de Chaves ocorreu por volta de 1946. A origem da emergência dessa abordagem social, além de relacionada a determinados fatores, tais como o processo de redemocratização da sociedade brasileira do pós-1945 e o início da rivalidade acadêmica com Castro, pode estar associada à própria atuação de Chaves como diretor geral do Departamento de Saúde Pública de Pernambuco no período de 1940 a 1943 e, posteriormente, como secretário de saúde e assistência social do Estado de Pernambuco no período de 1949 a 1951 (Costa, 1995a), cargos que propiciaram e/ou exigiram uma ampliação dos campos de conhecimento e atuação deste cientista, para além das fronteiras da dimensão exclusivamente biológica, característica da Fisiologia e da Endocrinologia. Acrescente-se que, em 1941, ele abandonou sua clínica particular, na cidade do Recife, onde exercia atividades médicas na especialização de Endocrinologia e Nutrição, desde 1932 (Coêlho, 1983).

Enfim, ao analisarmos as obras de Freyre, Castro e Chaves, observamos que todos eles compartilhavam da matriz ideológica que, à época, procurava desfocar da questão racial para a questão sócio-cultural o preconceito racial/climático que se tinha sobre o povo brasileiro, particularmente sobre o processo de mestiçagem. Sendo assim, podemos dizer que estes cientistas integraram-se perfeitamente à categoria mais ampla de intelectuais que, nos anos 1930-1940, imbuíram-se na tortuosa tarefa de construção da nacionalidade brasileira. Neste mesmo recorte, identificamos a emergência de pontos de tensão entre as abordagens de Freyre e Castro e de Chaves e Castro e que podem ser analisados, de acordo com a concepção estrutural construtivista de Bourdieu (1994) sobre a natureza do conhecimento e da prática científica, como fenômenos inerentes à chamada luta simbólica pelo estatuto científico sobre uma determinada área de conhecimento, disciplina ou campo intelectual. Assim, em Geografia da Fome, ao afirmar o caráter não científico que teria a obra de Freyre
(1998), por este não ter domínio nem usar a linguagem específica dos assuntos de alimentação, Castro (1980) reclamava para si o estatuto científico em falar e agir legitimamente no campo da Nutrição. Já em Casa Grande \& Senzala, ao apontar que determinadas conclusões sobre os hábitos e o padrão alimentar da população brasileira, as quais Castro teria chegado, eram inteiramente erradas, Freyre (1998) reivindicava o estatuto científico do método sociológico. Por outro lado, o embate acadêmico entre Chaves e Castro, iniciado nos anos 1940, tendo como alvo a competência científica sobre o conhecimento do valor biológico-nutricional e da utilização da mucunã vermelha (Dioclea grandiflora Benth.) na nutrição humana (Chaves et al. 1948; Chaves \& Lima, 1949; Castro, 1959; Castro, 1980), expressou, de forma bastante nítida, os conflitos existentes entre as duas principais vertentes conformadoras do campo da Nutrição: a biológica e a social.

\section{O nascimento (1950-1963)}

Os anos 1950-1963 foi o momento em que, sob a liderança de Chaves, foram criados o Instituto de Nutrição da UFPE (INUFPE), o então Curso de Nutricionistas e os Cursos de Especialização em Nutrição em Saúde Pública para médicos. Portanto, foi quando ocorreu o processo de graduação acadêmica dos docentes investigados que constituíram o núcleo inicial do campo da Nutrição em Saúde Pública do INUFPE, com exceção de um deles, Arruda, cuja graduação e uma primeira pós-graduação (especialização em Saúde Pública) ocorreram na segunda metade dos anos $40_{\mathrm{s}}$. Ao final deste recorte, Monteiro e Coêlho, especializaram-se no campo da Nutrição em Saúde Pública pelo Instituto de Nutrición de Centro América y Panamá (INCAP) da Guatemala, colocando-se entre as primeiras nutricionistas brasileiras detentoras desta modalidade de conhecimento. Sob a influência de organizações internacionais, tais como o Interdepartmental Committee on Nutrition for National Development (ICNND) e a Agency for International Development (USAID) dos EUA, Chaves e seu grupo começaram o desenvolvimento de pesquisas fora dos laboratórios do INUFPE e descobriram os elevados índices de Desnutrição Protéico-Calórica (DPC) grave das crianças na Zona da Mata Pernambucana. Descoberta que passaria a ser o principal objeto de estudo e intervenção deste grupo nos anos subseqüentes, deslocando o eixo de atuação destes cientistas do laboratório para a comunidade (Coêlho, 1983; Costa 1995a).

Em relação à análise da trajetória de vida de Castro, observamos que este foi um período de intensa ação político-intelectual deste cientista, quando evidenciamos tanto a sua organicidade intelectual junto ao Estado Populista, como sua projeção internacional enquanto membro dirigente da Food and Agriculture Organization (FAO), e sobretudo sua militância político-partidária. Neste período, seu pensamento e sua linha de investigação 
nutricional ganharam ressonância em Pernambuco, a partir da atuação de outros cientistas locais, tais como Jamesson Ferreira Lima, José Nivaldo Barbosa de Souza e Orlando Parahym, os quais, nas publicações que analisamos, ao mesmo tempo que identificaram-se com as características centrais da perspectiva social do campo da Nutrição, distinguiram-se das características do grupo de cientistas liderados por Chaves, cujas investigações desenvolvidas até então, associaram-se à perspectiva biológica.

Em relação à análise da produção científica de Chaves, observamos que o estudo das proteínas, sob o ponto de vista fisiológico, constituiu o paradigma central das investigações desenvolvidas por este cientista e seus assistentes. Quanto às obras institucionais criadas sob sua direção, acreditamos que seria interessante fazer um paralelo não apenas com as instituições criadas sob a orientação de Castro nos anos 40s (o Instituto de Nutrição, o Curso de Nutricionistas e os Cursos para Nutrólogos da Universidade do Brasil), mas com outras instituições semelhantes já existentes no Brasil e no Exterior. A partir da criação de tais instituições, Chaves procurava dotar o Estado de Pernambuco, ou mesmo o Nordeste, de um centro de ensino, pesquisa e extensão em Nutrição, não apenas articulado e dependente, mas com plenas condições de competir com seus similares nacionais e internacionais. Entretanto, num contexto marcado pelo ideário desenvolvimentista, onde a industrialização colocava-se como panacéia para solução da pobreza, da fome e das desigualdades regionais, a criação de tais instituições extrapola as fronteiras dos interesses pessoais do cientista Chaves, bem como as fronteiras de sua rivalidade acadêmica com Castro.

Além da dinâmica interna do contexto local/ regional, procuramos indicar que o processo de emergência ou nascimento da Nutrição em Saúde Pública em Pernambuco ocorreu sob forte influência internacional, representada pela realização do Nutrition Survey do ICNND, pelo desenvolvimento do Programa Alimentos para a Paz e por outras orientações de organizações internacionais como FAO, Organização Mundial da Saúde (OMS) e Organização Panamericana (OPAS).

A análise dos elementos empíricos investigados nos coloca muito mais próximos da concepção de campo científico como o espaço da luta pelo estatuto científico, cujas autonomia e legitimidade elevam-se à medida que aumentam o crédito científico dos produtores de bens simbólicos (os cientistas) e o nível de especialização dos conhecimentos produzidos, proposta por Bourdieu (1994). Ao mesmo tempo, provoca nosso afastamento da noção de comunidade científica como uma estrutura autônoma e auto-reprodutora, onde os cientistas agem de forma pacífica, neutra e desinteressada em nome do progresso científico, conforme concebida por Kuhn (1997). Observamos que tanto pelas obras institucionais criadas, como pela intensa produção intelectual, Chaves manteve-se como autoridade científica máxima, ocupando legitimamente a posição dominante entre seus pares produtores/ consumidores de bens simbólicos (ou de capital científico). A nível nacional, o crédito científico por ele conquistado neste período, aliado ao capital científico acumulado ao longo de sua trajetória, também conferiu a este cientista uma posição de destaque no campo da Nutrição brasileira. Neste nível (o nacional) permaneceu evidente o conflito entre Chaves e Castro, cientista que, ao longo deste recorte, manteve-se como autoridade científica máxima do campo da Nutrição no país, além de projetar-se no contexto internacional. Em relação ao núcleo inicial de docentes que iriam constituir o campo da Nutrição em Saúde Pública em Pernambuco, seguindo as orientações teóricas de Bourdieu (1994), podemos assinalar que neste momento teve início o chamado processo de acumulação primitiva do capital científico em Nutrição para todos os seus integrantes, caracterizado pela aquisição dos primeiros títulos acadêmicos e pela inserção na atividade científica profissional. Destacamos ainda que apesar do ingresso e da socialização destes novos membros à comunidade científica investigada terem sido feitos quase que exclusivamente sob a anuência de Chaves, o processo de treinamento destes cientistas não foi totalmente endógeno, à medida que alguns membros desta primeira geração buscaram capacitação em outros centros nacionais e internacionais, contrariando a idéia kuhniana de isolamento e autoreprodução da prática científica. E mais, a análise das duas principais práticas científicas que investigamos neste período (o Nutrition Survey do ICNND e o Programa Alimentos para a Paz da USAID) sugere que tais atividades foram desenvolvidas sob a influência de diferentes interesses produzidos e exigidos interna e externamente pela comunidade científica investigada, denotando, de certa forma, a gênese histórico-social do processo de constituição do campo da Nutrição em Saúde Pública em Pernambuco.

\section{O Crescimento (1964-1972)}

Nos anos 1964-1972, com a criação da Divisão de Nutrição em Saúde Pública do INUFPE, foi o momento em que ocorreram tanto a constituição do núcleo inicial de docentes voltados ao campo da Nutrição em Saúde Pública, como o processo de "uniformização" da capacitação acadêmica dos seus componentes neste campo específico do saber. Ou seja, pelo menos mais três componentes desta primeira geração especializaram-se neste campo específico: Arruda e Batista Filho realizaram o Curso de Especialização em Nutrição em Saúde Pública, para médicos, promovido pelo INUFPE, enquanto Baez realizou o curso do INCAP. Este foi o momento em que melhor caracterizou-se uma ação prática do grupo no campo da Nutrição em Saúde Pública, a partir do desenvolvimento dos Centros de Educação e Recuperação Nutricional (CERN) e do programa de Suplementação Alimentar Supervisada (SAS). 
Em termos de produção intelectual, verificou-se o início das primeiras publicações dos componentes deste núcleo inicial, as quais em sua ampla maioria retratam os resultados das pesquisas nutricionais desenvolvidas na Zona da Mata pernambucana (Costa, 1995a; Costa, 1995b). Com o exílio de Castro, Chaves passou a ser o principal porta-voz do campo da Nutrição em Pernambuco e até mesmo no Brasil. Em sua comunidade científica específica, manteve-se como autoridade científica máxima, ocupando a posição superior na hierarquia de produção dos bens simbólicos. Entretanto, no interior desta comunidade científica começou a evidenciar-se um previsível processo de diferenciação ou de divisão social do trabalho entre seus componentes, processo este que possibilitou a ascensão de determinados agentes sociais aos cargos superiores estabelecidos no interior desta estrutura acadêmica (direção, coordenação, chefia, presidência, etc.). Ascensão esta, ao que tudo indica, conquistada a partir de uma multiplicidade de fatores que não se reduziram à quantidade e/ou qualidade do crédito científico acumulado. Além deste, nos parece que estiveram em jogo interesses político-ideológicos e econômico-sociais produzidos no interior e/ou fora dos limites institucionais do INUFPE. E mais, a análise dos elementos empíricos investigados nos possibilitou constatar que a dinâmica da produção e aplicação prática dos conhecimentos científicos esteve neste período, muito mais do que antes, articulada à dinâmica e aos interesses de outras instituições, centros, comunidades ou campos científicos. Ou seja, neste período identificamos uma intensificação do chamado processo de intercâmbio científico entre o INUFPE e outras instituições nacionais e internacionais. Como exemplo, apontamos o estabelecimento de convênios com as OMS/OPAS que possibilitou, entre outras atividades, a criação dos Cursos de Especialização em Nutrição em Saúde Pública para médicos e a atuação do cientista belga Ivan Beghin junto ao núcleo de docentes da Divisão de Nutrição em Saúde Pública desta instituição. Portanto, este foi o momento onde ocorreu a efetiva institucionalização do campo da Nutrição em Saúde Pública em Pernambuco, tanto a nível acadêmico como a nível do aparelho do Estado. Este processo caracterizou-se pela produção de um corpo de conhecimentos científicos específicos sobre a epidemiologia da desnutrição protéico-calórica e de outras carências nutricionais da região; pela formação/ capacitação de um núcleo inicial de agentes sociais construtores/detentores deste capital científico; pela aplicação prática destes conhecimentos científicos através da implantação dos programas de intervenção nutricional e pela publicação/divulgação desta produção científica, o que garantiu a legitimidade ou reconhecimento social desta área de conhecimento específico no interior do campo da Nutrição brasileira.

Quando analisamos a trajetória acadêmico-intelectual de Chaves, identificamos uma fase inicial situada nos anos 1964-1968, contexto de relativa liberdade de expressão dentro da ditadura militar, caracterizada sobretudo pela publicação de artigos em jornais, assumindo um certo tom de denúncia das condições de miséria e de fome existentes no Nordeste brasileiro, particularmente em Pernambuco. Na segunda fase identificada, situada no período 1968-1972, sob os efeitos repressivos do Ato Institucional $\mathrm{n}^{\circ} 5$ (Al-5) e do Decreto-Lei $\mathrm{n}^{\circ} 477$, observamos além da recorrência à temática biológica, a ausência ou o abrandamento das críticas sociais nas publicações deste autor. Por outro lado, e em simultâneo, quando analisamos a trajetória acadêmico-intelectual dos docentes do INUFPE que emergiram no período 1968-1972 no campo da Nutrição em Saúde Pública em Pernambuco, observamos a ausência de discussão de temas sociais em suas publicações. À primeira vista, isto poderia nos levar a identificar uma falta de politização destes cientistas. Entretanto, levando em consideração o contexto histórico em que ocorreu a emergência desta nova geração de cientistas, torna-se compreensível a ausência de tais temáticas nestas suas primeiras publicações.

\section{A Reprodução (1973-1982)}

Nos anos 1973-1982 ocorreu um novo processo de aperfeiçoamento acadêmico do grupo de docentes investigados, quando todos, com exceção de Arruda, realizaram pós-graduação (mestrado e/ou doutorado) no campo da Nutrição em Saúde Pública. Neste momento, os dois principais instrumentos que caracterizaram a ação prática e/ou política dos cientistas do INUFPE foram a implantação do Curso de Mestrado em Nutrição em Saúde Pública e a instituição do II Programa Nacional de Alimentação e Nutrição (II PRONAN), sob à presidência de Arruda (Costa, 1995a). O mestrado, criado em 1971, foi o principal locus de produção e/ou reprodução de novos conhecimentos e agentes sociais neste campo do saber científico. O II PRONAN, por um lado, foi o instrumento que possibilitou a institucionalização de ações de Nutrição em Saúde Pública no interior da rede pública de serviços de saúde, educação, assistência social etc. em todo território nacional. Por outro lado, foi um dos principais instrumentos do processo de reprodução ampliada de nutricionistas no Brasil. Em termos de produção de conhecimento científico, foi o momento onde melhor caracterizou-se a ação intelectual do grupo, com a intensificação quantitativa e qualitativa das suas publicações, bem como a demarcação de domínios específicos de conhecimento no interior do próprio campo. Neste período, o paradigma ecológico-humanista da questão nutricional brasileira, construído por Chaves e seus pares ao longo das décadas anteriores, consagrou-se dominante em todo o território nacional, pelo menos até o ano de 1984, quando viu-se destronado da condução da principal agência governamental deste campo, dando margem à construção de novos paradigmas (Vasconcelos, 1999b). 
Em relação à trajetória acadêmico-intelectual de Chaves, tornou-se evidente o processo de movimentação das concepções deste autor entre o biológico e o social, o técnico e o político, o regional e o universal. Foi neste movimento teórico-conceitual que identificamos uma maior aproximação deste cientista com as idéias de Castro. Outras evidências assinaladas precisam ser destacadas, embora correndo o risco de estarmos com isso contribuindo para o processo de mitificação deste cientista. Entre os seus 70 a 76 anos de idade, Chaves desenvolveu suas últimas atividades administrativas, assumindo tanto a chefia do Departamento de Nutrição como a coordenação do Curso de Mestrado; manteve-se na posição majoritária em relação à produção científica do seu grupo e publicou a obra síntese de sua trajetória, o clássico Nutrição Básica e Aplicada (Chaves, 1978). Ao tomarmos esta obra como objeto de análise, assinalamos que a mesma tornou-se uma das principais referências bibliográficas, conforme identificou Bosi (1988), do processo didático-pedagógico de formação do nutricionista brasileiro nos anos 1980 . Além disso, Nutrição Básica e Aplicada se constituiu num dos principais veículos de circulação das idéias do grupo de cientistas do INUFPE, contribuindo para definir, pelo menos no período que analisamos, quais os problemas e os métodos legítimos do campo da Nutrição em Saúde Pública no Brasil. Ou seja, a visão ecológico-humanista acerca dos métodos de diagnóstico, prevenção e tratamento do processo fome/desnutrição, contida nesta obra, constituir-se-ia a partir de então no paradigma dominante da Nutrição no Brasil, seja como ciência, política social e/ ou profissão.

Em relação à análise da produção científica dos professores vinculados ao campo da Nutrição em Saúde Pública, observamos que consolidou-se o processo de divisão e especialização do saber/trabalho entre eles. Ou seja, observamos que entre 1968 (ano das suas primeiras publicações) e 1982 (último ano investigado), este campo específico da Nutrição foi sendo gradativamente partilhado em áreas temáticas específicas de saber/agir entre os seus componentes. Muito embora tal partilha identificada não signifique necessariamente a demarcação de fronteiras rígidas de competência e/ou autoridade científicas entre eles, uma vez que determinadas áreas temáticas aparecem como objetos de estudo/trabalho de mais de um dos membros do grupo. Arruda, em função do cargo ocupado - presidência do Instituto Nacional de Alimentação e Nutrição (INAN), centralizou sua produção científica na área temática Política de Alimentação e Nutrição, além de manter uma linha de publicações sobre Formação de Recursos Humanos com ênfase no Nutricionista. Monteiro transformou a Educação Nutricional na temática central da sua trajetória de produção científica, além da linha de pesquisa sobre Aleitamento Materno, introduzida com sua dissertação de mestrado, que garantiu especificidade temática a esta autora, em relação aos demais membros do grupo. Coêlho compartilhou um amplo leque de conteúdos temáticos em suas publicações, destacando-se: Diagnósticos Nutricionais de Populações;
Determinantes Sócio-econômicos da Desnutrição e Programas de Nutrição em Saúde Pública. Batista Filho, de acordo com as listagens contidas em Costa (1995b), em termos quantitativos, foi o líder do grupo dos docentes vinculados ao campo da Nutrição em Saúde Pública, além de apresentar o maior leque de conteúdos temáticos das publicações, onde pelo menos quatro linhas de investigações foram identificadas: Diagnósticos Nutricionais de Populações; Indicadores Antropométricos do Estado Nutricional; Epidemiologia da Desnutrição Protéico Calórica e de outras Carências Nutricionais Específicas e Programas de Diagnóstico, Tratamento e Prevenção da Hipovitaminose A e das Anemias Nutricionais. Lucena centralizou sua produção científica na temática Avaliação Nutricional de Populações, apesar de compartilhar publicações sobre outros temas, tais como Tratamento e Recuperação de Desnutridos; Ensino de Graduação em Nutrição e Ações e Atividades do Nutricionista. Baez, por sua vez, centralizou sua trajetória de produção científica na temática Supervisão de Programas de Nutrição em Saúde. Embora não tenha sido enunciado claramente por todos, mas tenha sido explicitado pela maioria, observamos que o paradigma que unificou este grupo de pesquisadores do INUFPE foi a concepção ecológico-humanista centrada na inter-relação de fatores epidemiológicos relacionados à produção, ao consumo e ao aproveitamento biológico dos alimentos pelos chamados grupos biológica e socialmente vulneráveis à desnutrição.

No período em apreço consolidou-se a chamada Reforma Universitária, imposta pelos governos militares, e o INUFPE também foi submetido ao processo de transformação da sua estrutura organizacional, administrativa e pedagógica, pela qual passou a UFPE. Embora em nossa investigação não tenhamos aprofundado esta questão, acreditamos que determinados preceitos introduzidos no ensino superior com a referida reforma, tais como a departamentalização do saber, a dicotomização do ensino de graduação em ciclo básico e ciclo profissionalizante e a ênfase na chamada pedagogia tecnicista, devem ter tido uma forte influência na trajetória acadêmico-intelectual do grupo de docentes do INUFPE que se consolidou neste período.

\section{CONSIDERAÇÕES FINAIS}

Nos dias atuais, observamos que ao perfil epidemiológico nutricional que foi traçado ao longo dos anos 1930-1982 por Castro, Parahym, Ferreira Lima, Chaves e tantos outros cientistas que deram origem e conformação à Nutrição em Saúde Pública, caracterizado sobretudo pelas chamadas doenças carenciais (desnutrição protéico-calórica, hipovitaminose A, pelagra, anemia ferropriva e outras), sobrepuseram-se as chamadas doenças nutricionais degenerativas (obesidade, diabetes, dislipidemias etc.). Diante da globalização da Nutrição e/ou das doenças nutricionais, processo que traz em seu 
bojo a uniformização planetária dos hábitos e práticas alimentares, onde a produção e a circulação da mercadoria alimento permanece atrelada às necessidades de acumulação do capital e não às necessidades nutricionais humanas, novos dilemas nos são colocados. Nos anos 1930-1950, ao traçar a Geografia da Fome no país, Castro e seus pares conseguiram contar com as ambigüidades e contradições do Estado Populista brasileiro que tomou a questão nutricional como uma das principais temáticas de sua agenda. Nos anos 1970-1980, a degradação das condições de vida, saúde e nutrição da população brasileira, atestada pelo Estudo Nacional da Despesa Familiar (ENDEF), conseguiu sensibilizar o Estado Autoritário brasileiro que tomou, dentro das diretrizes do II PRONAN, a questão nutricional como um dos principais instrumentos do discurso de desenvolvimento econômico-social do país. Nos anos 1990, apesar do processo de (re)descoberta da fome e da consistente pressão da Ação da Cidadania contra a Fome, a Miséria e pela Vida, observamos um significativo esvaziamento da questão nutricional enquanto temática da agenda pública. Neste sentido, urge perguntar: qual será a questão (paradigma) nutricional a ser colocada na agenda pública brasileira do terceiro milênio? Confesso que permaneço dividido entre os dilemas do Pão ou Aço e Aterosclerose e Nutrição, colocados, respectivamente, por Castro e Chaves nos anos 1950-1960. Laboratório e/ou população? Ciência e/ou política? Biológico e/ou social? A história não acaba aqui. A luta simbólica continua!

\section{AGRADECIMENTOS}

Ao professor Dr. Ricardo Ventura Santos (Escola Nacional de Saúde Pública, Fundação Oswaldo Cruz), pela prestimosa orientação.

\section{REFERÊNCIAS BIBLIOGRÁFICAS}

BOSI, M.L.M. A face oculta da nutrição: ciência e ideologia. Rio de Janeiro : Espaço e Tempo, 1988. 220 p.

BOURDIEU, P. El campo científico. Revista de Estudios Sociales de la Ciencia (Redes), Buenos Aires, v.1, n.2, p.131-160, 1994.

CASTRO, J. Novas pesquisas sobre a mucunã. In: Castro, J. Documentário do Nordeste. 2. ed. São Paulo : Brasiliense, 1959. p.183-213.

CASTRO, J. Geografia da fome: o dilema brasileiro: pão ou aço. 10.ed. Rio de Janeiro: Antares, 1980. 361p.

CHAVES, N., TEODÓSIO, N.R., LIMA, O.G., PESSOA, W. A mucunã vermelha (Dioclea grandiflora Benth.) na Nutrição.
Recife : Universidade do Recife, 1948. 74p. (Laboratório de Fisiologia da Faculdade de Medicina).

CHAVES, N., LIMA, O.G. A mucunã vermelha na Nutrição: novos comentários. Recife : Imprensa Oficial, 1949. 17p.

CHAVES, N. Nutrição básica e aplicada. Rio de Janeiro : Guanabara Koogan, 1978. 344 p.

COÊLHO, H.A.L. Formação do profissional nutricionista na América Latina e no Brasil, com ênfase em Pernambuco. Revista Alimentação e Nutrição, São Paulo, v.4, n.11, p.47-51, 1983.

COIMBRA, M., MEIRA, J.F.P., STARLING, M.B.L. Comer e aprender: uma história da alimentação escolar no Brasil. Belo Horizonte : MEC, 1982. 685p.

COSTA, M.C.M.A. (Org.). Quarenta anos de nutrição no Nordeste: uma retrospectiva. Recife : Editora Universitária da UFPE, 1995a. 441p.

COSTA, M.C.M.A. (Org.). Memória científica do Departamento de Nutrição e das instituições predecessoras (1950-1966). Recife : Editora Universitária da UFPE, 1995b. 240p.

FREYRE, G. Casa-grande e senzala. 34.ed. Rio de Janeiro : Record, 1998. 569p.

KUHN, T.S. A estrutura das revoluções científicas. 5.ed. São Paulo : Perspectiva, 1997. 257p.

L'ABBATE, S. Fome e desnutrição: os descaminhos da política social. São Paulo, 1982. 204p. Dissertação (Mestrado em Sociologia) - Departamento de Ciências Sociais, Faculdade de Filosofia Letras e Ciências Humanas, Universidade de São Paulo, 1982.

LIMA, E.S. Gênese e constituição da educação alimentar: a instauração da norma. São Paulo, 1997. 407p. Tese (Doutorado em Educação) - Pontifícia Universidade Católica de São Paulo, 1997.

MAGALHÃES, R. Fome: uma (re)leitura de Josué de Castro. Rio de Janeiro : Fiocruz, 1997. 87p.

VASCONCELOS, F.A.G. Os Arquivos Brasileiros de Nutrição: uma revisão sobre produção científica em nutrição no Brasil (1944 a 1968). Cadernos de Saúde Pública, Rio de Janeiro, v.15, n.2, p.303-316, 1999a.

VASCONCELOS, F.A.G. Como nasceram os meus anjos brancos: a constituição do campo da Nutrição em Saúde Pública em Pernambuco. Rio de Janeiro, 1999. 266p. Tese (Doutorado em Saúde Pública) - Escola Nacional de Saúde Pública, Fundação Oswaldo Cruz, 1999b.

YPIRANGA, L., GIL, M.F. Formação profissional do nutricionista: por que mudar? In: CUNHA, D.T.O., YPIRANGA, L., GIL, M.F. (Org.). Seminário Nacional sobre o Ensino de Nutrição. Goiânia : FEBRAN, 1989. p.20-36.

Recebido para publicação em 21 de julho de 2000 e aceito em 15 de fevereiro de 2001. 